\title{
Urinary Tract Infection Among Prison Inmates in Afara Jail Umuahia
}

\author{
Ezeagwula Divine ${ }^{1}$, Nwachukwu Ndubuisi ${ }^{1, ~ *, ~ N w a u g o ~ V i c t o r ~}{ }^{1}$, Ulasi Amara ${ }^{2}$ \\ ${ }^{1}$ Department of Microbiology, Faculty of Biological Sciences, Abia State University, Uturu, Nigeria \\ ${ }^{2}$ Department of Animal and Environmental Biology, Faculty of Biological Sciences, Abia State University, Uturu, Nigeria
}

\section{Email address:}

treasurekingwhite@gmail.com (E. Divine),nwachukwundubuisi82@yahoo.com (N. Ndubuisi), vonwaugo@yahoo.com (N. Victor), amaraesther@gmail.com (U. Amara)

${ }^{*}$ Corresponding author

\section{To cite this article:}

Ezeagwula Divine, Nwachukwu Ndubuisi, Nwaugo Victor, Ulasi Amara. Urinary Tract Infection Among Prison Inmates in Afara Jail Umuahia. International Journal of Clinical Urology. Vol. 4, No. 1, 2020, pp. 25-29. doi: 10.11648/j.ijcu.20200401.16

Received: February 27, 2020; Accepted: March 10, 2020; Published: April 8, 2020

\begin{abstract}
Urinary tract infections are the most commonly encountered bacterial infections in clinical practice. It is yet to be fully explored in prisons. We determined the prevalence of urinary tract infection among prison inmates at Afara Jail Umuahia, Nigeria. A cross-sectional study was conducted among 218 prison inmates. Freshly-voided mid-stream urine from each inmate was cultured on MacConkey agar and $5 \%$ Blood agar and incubated at $37^{\circ} \mathrm{C}$ for $24 \mathrm{~h}$. Isolates were identified by standard microbiological techniques. Antimicrobial susceptibility testing was performed by Kirby-Bauer disc diffusion method. Data were analyzed using SPSS version 17 package and the Chi-square test. The prevalence of urinary tract infection was $22.0 \%$. The commonly isolated bacteria were Escherichia coli (33.3\%), Klebsiella pneumoniae (20.8\%), and Staphylococcus aureus (18.8\%). Exactly $72.9 \%$ of isolates were Gram negative bacilli and $27.1 \%$ Gram positive cocci $(\mathrm{P}<0.05)$. Gram negative isolates were more sensitive to Gentamicin (97.1\%) followed by Zithromax (88.6\%). Gram positive cocci showed maximum sensitivity to Ciprofloxacin (92.3\%) and Gentamicin (92.3\%). All Gram positive cocci were resistant to Tetracycline and Ampicillin. Females were more infected $(56.6 \%)$ than males $(17.9 \%)(\mathrm{P}<0.05)$. The prevalence of urinary tract infection in Afara prison was $22.0 \%$. Escherichia coli was the commonest isolate. Gentamicin and Ciprofloxacin were the most useful antibiotics and could be used as first line drugs for treatment of Urinary tract infection among prison inmates.
\end{abstract}

Keywords: Urinary Tract Infection, Prison Inmates, Antibiotic Susceptibility Testing, Afara Jail, Nigeria

\section{Introduction}

A prison is a facility used for the confinement of prisoners under the authority of the State. It is seen either as punishment for crimes committed or mode of rehabilitation $[1,2]$. The normal life of inmates is restricted, freedom of movement is curtailed and private space is limited.

Prisoners in developing countries live in extremely poor conditions. Due to dilapidated facilities, the risk of acquiring, activation or aggravation of already existing infection usually increases in prisons [3]. Prisoners are more susceptible to disease owing to poor healthcare, overcrowding, high risk behaviors, poor nutrition, lack of potable water, poor personal and environmental hygiene and low level immunity due to stress $[4,5]$.
Urinary tract infections are commonly encountered by clinicians in developing countries, with an estimated annual global incidence of 250 million [6, 7]. Urinary tract infections have been studied extensively in diverse communities and among different age groups [8-10] but it is yet to be fully explored in prison inmates whose health are often neglected.

This study therefore, seeks to determine the prevalence of urinary tract infection among prison inmates of Afara Federal prisons Umuahia, Nigeria.

\section{Materials and Methods}

\subsection{Study Area}

This cross-sectional study was conducted among prison 
inmates of Afara Federal Prisons, Umuahia, Abia State, Nigeria between July 2017 and October, 2018. Afara Federal Prisons Umuahia is a Minimum Prison located in the capital of Abia State and serves the South- eastern parts of Nigeria.

\subsection{Study Participants}

A total of 218 prisoners participated. Age of the subjects ranged from 21 years to 60 years.

\subsection{Methods}

The socio-demographic characteristics of the inmates were obtained using structured questionnaires. Urine samples were collected from each participant. Prior to urine collection, participants were instructed on how to aseptically collect a clean catch mid-stream urine into a sterile screw-cap universal container to avoid contamination.

\subsection{Sample Processing}

The bacterial counts in the urine samples were determined by semi-quantitative method using a calibrated inoculation loop of $4 \mathrm{~mm}$ internal diameter. A loopful $(0.001 \mathrm{ml})$ of midstream urine was inoculated unto the surface of well-dried MacConkey agar and 5\% Blood agar plates. After overnight incubation at $37^{\circ} \mathrm{C}$, culture plates that yielded bacterial counts of $>10^{5} \mathrm{CFU} / \mathrm{ml}$ were considered as significant [11]. Isolated organisms were characterized and identified using standard laboratory methods including colonial appearance, microscopy and biochemical techniques [11]. Corresponding ATCC strains were used as reference standard during biochemical identification of isolated uropathogenic bacteria.

\subsection{Antibiotic Susceptibility Testing}

Antibiotic susceptibility testing was performed by the Kirby-Bauer disc diffusion method [12]. Ten commercially available antibiotic discs were used at their respective concentrations and include Ciprofloxacin $(10 \mu \mathrm{g})$, Gentamicin (10mg), Norfloxacin $(10 \mu \mathrm{g})$, Amoxil $(30 \mu \mathrm{g})$, Tetracycline (30 $\mu \mathrm{g})$, Erythromycin $(30 \mu \mathrm{g})$, Nalidixic acid $(30 \mu \mathrm{g})$, Ampicillin $(10 \mu \mathrm{g})$, Streptomycin $(30 \mu \mathrm{g})$ and Zithromax $(10 \mu \mathrm{g})$. After seeding respective test organism on Muller Hinton Agar plate and with the aid of a sterile forceps, each antibiotic disc was placed on the surface of the medium. The diameter of inhibition zone around the disc was recorded after incubation at $37^{\circ} \mathrm{C}$ for $24 \mathrm{~h}$. The reference standard was used for the inspection of isolate sensitivity/resistance pattern. The results of the antibiotic susceptibility tests were interpreted following the National Committee for Clinical Laboratory Standards [13].

\subsection{Data Analysis}

The data were analyzed using SPSS version 17 package. Frequency tables were obtained for selected variables and statistical test of significance was performed using Chisquare test. $\mathrm{P}<0.05$ was considered statistically significant.

\subsection{Ethical Clearance}

Ethical clearance was sought and obtained from the Chief Comptroller of Prisons. A support letter from Abia State University was also sent to the Chief Comptroller of Prisons. Inmates consented to participate in the study.

\section{Results}

A total of 218 prison inmates, whose age ranged from 21 years to 66 years enrolled in the study. Majority of the inmates were males $(89.4 \%)$. Urinary tract infection affected more females $(56.5 \%)$ than males $(17.9 \%)(\mathrm{P}<0.05)$. The age group most infected were $30-39$ year old $(25.0 \%)$ while the least infected were those 60 years and above $(0 \%)(\mathrm{P}<0.05)$. Illiterate prison inmates $(25.0 \%)$ and the ones who completed primary school only $(25.4 \%)$ had the highest prevalence of urinary tract infection. The length of time in prison is significantly associated with urinary tract infection. Inmates incarcerated for more than 10 years were most infected (29.4\%) as presented in Table 1.

Out of the 218 urine samples examined, 48 (22.0\%) yielded bacterial counts $>10^{5} \mathrm{CFU} / \mathrm{ml}$, indicating significant growth of uropathogens. Exactly $72.9 \%$ of the isolates were Gram negative bacilli while $27.1 \%$ were Gram positive cocci (Table 2).

As presented in Table 3, Escherichia coli was the most common isolate $(33.3 \%)$ followed by Klebsiella pneumoniae (20.8\%), Staphylococcus aureus $(18.8 \%)$ and the least frequent Pseudomonas aeruginosa (6.3\%).

Antibiotic susceptibility testing of Gram negative bacilli revealed that Gentamicin (97.1\%) was the most sensitive antibiotic. It was followed by Zithromax $(88.6 \%)$ and the least sensitive antibiotic was Streptomycin (8.6\%) (Table 4).

Results for the susceptibility pattern of Gram positive cocci showed that maximum sensitivity was seen in Ciprofloxacin (92.3\%) and Gentamicin (92.3\%). All the Gram positive cocci resisted Tetracycline and Amoxil (Table 5).

Table 1. Socio-demographic characteristics of inmates at Afara Prison, Umuahia.

\begin{tabular}{lll}
\hline Variable & No. examined (\%) & No. UTI positive (\%) \\
\hline Gender & & $35(17.9)$ \\
Men & $195(89.4)$ & $13(56.5)$ \\
Women & $23(10.6)$ & $1(11.1)$ \\
Age group (yr) & & $29(25.0)$ \\
$19-29$ & $9(4.1)$ & $16(21.6)$ \\
$30-39$ & $116(53.2)$ & $2(12.5)$ \\
$40-49$ & $74(34.0)$ & $16(7.3)$
\end{tabular}




\begin{tabular}{lll}
\hline Variable & No. examined (\%) & No. UTI positive (\%) \\
\hline $60+$ & $3(1.4)$ & $0(0)$ \\
Education & & \\
Illiterates & $96(44.0)$ & $24(25.0)$ \\
Completed primary school & $67(30.7)$ & $17(25.4)$ \\
Completed secondary school & $41(18.8)$ & $6(14.6)$ \\
Tertiary & $14(6.4)$ & $1(7.1)$ \\
Marital Status & & \\
Single & $129(59.2)$ & $26(20.2)$ \\
Married & $89(40.1)$ & $22(24.7)$ \\
Time in Prison (Yr) & & \\
$<1$ & $52(23.9)$ & $10(19.2)$ \\
$1-5$ & $132(60.6)$ & $28(21.2)$ \\
$>10$ & $34(15.6)$ & $10(29.4)$ \\
\hline
\end{tabular}

Table 2. Prevalence of urinary tract infection among Afara prison inmates.

\begin{tabular}{lllll}
\hline Total urine samples tested & $\begin{array}{l}\text { No urine samples positive } \\
\text { for UTI (\%) }\end{array}$ & No. GNB Isolated (\%) & No. GPC Isolated (\%) & $\begin{array}{l}\text { Total no. samples } \\
\text { negative for UTI (\%) }\end{array}$ \\
\hline 218 & $48(22.0)$ & $35(72.9)$ & $13(27.1)$ & $170(78)$ \\
\hline
\end{tabular}

GNB: Gram Negative Bacilli; GPC: Gram positive cocci.

Table 3. Distribution of uropathogens among Afara prison inmates ( $n=48)$.

\begin{tabular}{lll}
\hline Bacteria & Frequency & \% \\
\hline Escherichia coli & 16 & 33.3 \\
Klebsiella pneumoniae & 10 & 20.8 \\
Proteus sp & 6 & 12.5 \\
Pseudomonas aeruginosa & 3 & 6.3 \\
Gram Positive Cocci & & \\
Staphylococcus aureus & 9 & 18.8 \\
Streptococcus fecalis & 4 & 8.3 \\
\hline
\end{tabular}

Table 4. Antimicrobial susceptibility pattern of isolated Gram negative bacteria.

\begin{tabular}{llllll}
\hline Antibiotics & E. coli $(\mathbf{n}=\mathbf{1 6})$ & K. pneumonia $(\mathbf{n}=\mathbf{3})$ & P. aeruginosa $(\mathbf{n}=\mathbf{3})$ & Proteus sp $(\mathbf{n}=\mathbf{6})$ & Total $(\%)$ \\
\hline Gentamicin & 15 & 10 & 6 & 3 & $34(97.1)$ \\
Ciprofloxacin & 12 & 8 & 5 & 2 & $27(77.1)$ \\
Norfloxacin & 11 & 4 & 1 & 1 & $17(48.6)$ \\
Amoxil & 0 & 0 & 5 & 0 & $5(14.3)$ \\
Erythromycin & 2 & 0 & 1 & 3 & $6(17.1)$ \\
Nalidixic Acid & 9 & 3 & 0 & 0 & $12(34.3)$ \\
Ampicillin & 0 & 0 & 0 & 0 & $0(0)$ \\
Streptomycin & 0 & 0 & 1 & 2 & $3(8.6)$ \\
Zithromax & 14 & 6 & 3 & $31(88.6)$ \\
\hline
\end{tabular}

Table 5. Antimicrobial susceptibility pattern of isolated Gram positive cocci.

\begin{tabular}{llll}
\hline Antibiotics & S. aures $(\mathbf{n}=\mathbf{9})$ & S. fecalis $(\mathbf{n}=\mathbf{4})$ & Total $(\mathbf{\%})$ \\
\hline Gentamicin & 9 & 3 & $12(92.3)$ \\
Tetracycline & 0 & 0 & $0(0)$ \\
Ampicillin & 0 & 0 & $0(0)$ \\
Ciprofloxacin & 9 & 3 & $12(92.3)$ \\
Ceporex & 6 & 4 & $10(76.9)$ \\
Amoxil & 3 & 2 & $5(38.5)$ \\
Erythromycin & 4 & 2 & $6(46.2)$ \\
Streptomycin & 1 & 1 & $2(15.4)$ \\
Norfloxacin & 8 & 3 & $11(84.6)$ \\
\hline
\end{tabular}

\section{Discussion}

Urinary tract infections are recognized globally as the most prevalent bacterial infection in humans and a major public health concern [14]. Prisoners are generally more susceptible to diseases [5]. In our study, an overall prevalence of $22.0 \%$ was observed. This is similar to $21.4 \%$ obtained in an earlier study in Jos Main Prison, Nigeria [3]. However, it contracts with $9.9 \%$ recorded among prison inmates in central jail of Bhopal [5] and $0.67 \%$ in central jail of South India [2].

In this study, Gram negative bacilli constituted $72.9 \%$ of the total isolates while Gram positive cocci constituted $27.1 \%$. This finding agrees with other reports that Gram negative bacilli are the commonest pathogens isolated from patients with urinary tract infection [5, 15]. This high 
prevalence of Gram negative bacilli among prison inmates is also similar in other settings [16] and are due to the fact that the Enterobacteriaceae are primary agents causing urinary tract infection and has many factors responsible for their attachment to the uro-epithelium [16].

The most predominant organisms isolated from the inmates were Escherichia coli (33.3\%), Klebsiella pneumoniae (20.8\%) and Staphylococcus aureus (18.8\%). This is consistent with the study conducted by others in Nigeria [3, 5, 17]; Ethiopia (18) and Saudi Arabia [19]. Globally, Escherichia coli is envisaged to cause $70-95 \%$ upper and lower urinary tract infection [7].

Urinary tract infection occurred more in female inmates than male inmates. Urinary tract infection is more frequent in females than males during adolescence and adulthood [15]. It is universally agreed that frequency of urinary tract infection is especially high among women due to their reproductive physiology [20, 21].

Prison inmates incarcerated for more than 10 years had the highest prevalence of urinary tract infection in our study. Similar observation had been documented [3]. Prolonged incarceration may lead to more exposure to stress and low standard of living and eventually reduced immunity and disease [17].

Antibiotic susceptibility pattern of isolated bacteria showed high sensitivity of Gram negative bacilli to Gentamicin and Zithromax. Similar findings had been previously reported [22, 23]. Maximum resistance was shown to Amoxil. The most useful antibiotics against Gram positive cocci were Ciprofloxacin and Gentamicin. Resistance shown to Tetracycline and Ampicillin could be due to over-use and above of these antibiotics. In conclusion, the prevalence of urinary tract infection in Afara Prison was $22.0 \%$. Escherichia coli was the most implicated bacteria causing urinary tract infection and female prison inmates were mostly infected. Gentamicin and Ciprofloxacin were the most useful antibiotics for the treatment of urinary tract infection.

\section{References}

[1] Ndukwe, C. and Nwazor, C. I. (2014). Nigerian prison service and the challenges of social welfare administration; a study of Abakiliki prison. Journal of Policy and Development Studies 9: $20-27$.

[2] Kumar, S. D., Kumar, S. A., Pattankar, J. V., Reddy, S. B. and Dhar, M. (2013). Health status of the prisoners in a Central Jail of South India. India Journal of Psychololgical Medicine 35: 373-377.

[3] Essien, U. C., Ede, F. R., Idoko, E. J., Vem, T. S., Damen, J. G. and Sheyin, Z. (2017). Bacteriology of urinary tract infection among inmates of Jos main prison plateau state, Nigeria. European Journal of Pharmacy and Medical Research 4: $179-182$.

[4] Fraser, A (2007). Primary health care in prisons. In: Moller L, Gatherer A, Jurgens R, Stover H, Nikogosian H, editors: Health in prisons: a WHO Guide to the Essentials in Prison
Health. WHO Regional Office Europe, pp 21-31.

[5] Amit, D., Tripathi, K. and Nema, S. (2016). Prevalence of intestinal parasites and urinary pathogens among prison inmates in central jail of Bhopal (MP). Indian Journal of Microbiology Research 3: 47-52.

[6] Arnold, J. J., Hehn, L. E. and Klein, D. A. (2016). Common questions about recurrent urinary tract infections in women. Family Physicians 93: 560-569.

[7] Payam, B., Elham, B., Hodjjat, V. and Roghiyyen, A. A. (2010). Survey on urinary tract infections associated with the three most common uropathogenic bacteria. Medica (Buchar) 5: 111-115.

[8] Tosin, T. O., Akinwumi, A. A., Adeyemi, O. and Oluseyi, A. A. (2018). Urinary tract infections and antibiotics sensitivity pattern of uropathogens in a tertiary hospital in south West Nigeria. Sahel Medical Journal 18-22.

[9] Schaffer, A. J. and Nicolle, L. E. (2016). Clinical practice. Urinary tract infections in older men. New England Journal of Medicine 374: 562-571.

[10] Nema, S., Tripath, I. and Dhanvijay, A. K. (2013). Bacteriological profile and antibiogram of community and hospital acquired urinary tract infections in Medical College hospital of central India. International Journal of Medicine and Applied Science 2: 380-391.

[11] Forbes, B. A., Sahm, D. F. and Weissfield, A. S. (2002). Infections of the urinary tract. Bailey and Scotts Diagnostic Microbiology. $11^{\text {th }}$ ed, Mosby: vol 60, pp 927-938.

[12] Bauer, A. W., Kriby, W. M. M., Sheris, J. C. and Jurck, M. (1999). Antibiotic susceptibility testing by a standard single disc diffusion method. American Journal of Clinical Pathology 493-496.

[13] National Committee for Clinical Laboratory Standards (NCCLS). (2010). Performance standards for antimicrobial susceptibility testing $20^{\text {th }}$ Informational Supplement. M100S20. Clinical and Laboratory Standards Institute. Pennsylvania, USA.

[14] Tigist, G., Belayneh, R., Aseer, M. (2016). Prevalence, diversity and antimicrobial resistance of bacterial isolated from the UTI patients of Arba Minch Province, Southern Ethiopia. Translational Biomedicine 7: 3 .

[15] Mbata, T. I. (2006). Prevalence and antibiogram of UTIs among prison inmates in Nigeria. The Internet Journal of Microbiology 3: 2.

[16] Das, R. N., Channdrashekhar, T. S., Joshi, H. S., Gurung, M., Shrestha, N. and Shivananda, P. G. (2006). Frequency and susceptibility profile of pathogens causing urinary tract infections at tertiary care hospital in Western Nepal. Singapore Medical Journal 47: 281-285.

[17] Alo, M. N., Ugah, U. I., Saidu, A. Y. and Alhassan, H. M. (2015). Microbial status of prison inmates in Abakaliki Prison, Ebonyi State Southern Nigeria. Global Journal of Medical Research and Studies 2: 7-11.

[18] Biadglegne, F. and Abera, B. (2009). Antimicrobial resistance of bacterial isolates from urinary tract infections at FelgeHiwot Referral Hospital, Ethiopia. Ethiopian Journal of Health Development 23: 236-238. 
[19] Al-Tawfig, J. A. and Anani, A. A. (2009). Antimicrobial pathogens causing urinary tract infections in a Saudi Arabian hospital. Chemotherapy. 55: 127-131.

[20] Mody, L., Juthani, M. M. (2014). Urinary tract infection in older women; a clinical review. Journal of American Medical Association311: 844-854.

[21] August, S. L. and DeRosa, M. J. (2012). Evaluation of the prevalence of urinary tract infection in rural Panamanian women. Public Library of Science ONE e 7752.
[22] Saleh, A. A., Ahmed, S. S., Ahmed, M., Sattar, A. N. I. and Miah, M. R. A. (2009). Changing trends in uropathogens and their antimicrobial sensitivity pattern. Bangladesh Journal of Medical Microbiology 3: 9-12.

[23] Alzohariry, M. and Khadri, H. (2011). Frequency and antibiotic susceptibility pattern of uropathogens isolated from community and hospital acquired infections in Saudi Arabia a prospective case study. British Journal of Medical Research 1920: 45. 